\title{
Inhibitory effect of ailanthoidol on 12-O-tetradecanoyl-phorbol- 13-acetate-induced tumor promotion in mouse skin
}

\author{
YEAN-JANG LEE ${ }^{1}$, ERL-SHYH KAO ${ }^{2}$, CHIA-YIH CHU ${ }^{3}$, WEA-LUNG LIN ${ }^{4}$, \\ YEA-HUEY CHIOU ${ }^{2}$ and TSUI-HWA TSENG ${ }^{3}$
}

\begin{abstract}
${ }^{1}$ Department of Chemistry, National Changhua University of Education, Changhua; ${ }^{2}$ Institute of Biochemistry and Biotechnology, College of Medicine; ${ }^{3}$ School of Applied Chemistry, College of Health Management, Chung Shan Medical University; ${ }^{4}$ Department of Pathology, Chung Shan Medical University Hospital, Taichung, Taiwan, R.O.C
\end{abstract}

Received April 24, 2006; Accepted July 12, 2006

\begin{abstract}
Many components derived from dietary or medicinal plants showing antioxidant and anti-inflammatory potential have been found to possess chemopreventive properties. In our previous study, we achieved the total synthesis of ailanthoidol (AT), a neolignan from Zanthoxylum ailanthoides or Salvia miltiorrhiza Bunge, which are used in Chinese traditional herbal medicine. In the present study, preliminarily, AT exhibited a radical quenching property by DPPH assay. Following this, we assessed the effect of AT on 12- $O$ tetradecanoylphorbol-13-acetate (TPA)-induced oxidative stress and inflammation in female CD-1 mouse skin which was closely linked to tumor promotion. The topical application of AT (0.5-2.5 mM; $200 \mu \mathrm{l})$ reduced the formation of hydrogen peroxide and inhibited the myeloperoxidase (MPO) activity in the mouse skin when compared with that of the TPA-treated alone group. In addition, AT presented a suppression effect on the TPA-induced hyperplasia and leukocyte infiltration in the epidermis and edema of mouse ears. Furthermore, it showed that AT inhibited the TPA-induced expression of COX-2 protein and ornithine decarboxylase (ODC) activity in epidermis. Finally, AT was evaluated for its ability to inhibit the TPA-induced promotion in skin tumors of female CD-1 mice. Topical application of AT 5 min prior to TPA $(5 \mathrm{nmol})$ three times weekly for 12 weeks to mice which were initiated with benzo[a]pyrene $(\mathrm{B}[\mathrm{a}] \mathrm{P})$ inhibited the
\end{abstract}

Correspondence to: Professor Tsui-Hwa Tseng, School of Applied Chemistry, College of Health Management, Chung Shan Medical University, No. 110, Sec. 1, Chien Kuao N. Rd., Taichung, 402 Taiwan, R.O.C

E-mail: tht@csmu.edu.tw

Abbreviations: AT, ailanthoidol; TPA, 12-O-tetradecanoylphorbol13-acetate; $\mathrm{B}[\mathrm{a}] \mathrm{P}$, benzo[a]pyrene; $\mathrm{H}_{2} \mathrm{O}_{2}$, hydrogen peroxide; MPO, myeloperoxidase; $\mathrm{COX}-2$, cyclooxygenase-2

Key words: ailanthoidol, 12-O-tetradecanoylphorbol-13-acetate, skin tumor, anti-tumor promotion incidence of skin tumors in mice and the average number of tumors per mice as compared to TPA-treated alone. These results indicate that AT possesses potential as a chemopreventive agent against tumor promotion.

\section{Introduction}

In our previous study, we achieved the total synthesis of ailanthoidol (AT) (1), a neolignan from Zanthoxylum ailanthoides or Salvia miltiorrhiza Bunge (2,3), which are used in Chinese traditional herbal medicine. In addition, on chemical constituents of those species and their bioactivities, the lignans are dimmers of propylbenzene units that connect at the side chain carbon. Those whose linkage of two phenylpropanoid units is other than the above type are known as neolignans. Though lignans and neolignans have been reported to exhibit a broad range of biological activity, including antiviral (4), anticancer (5), anti-inflammation (6) and antioxidation (7), the biological activity of AT is not well understood.

Recently, considerable efforts have been made to search chemopreventive agents that could inhibit, retard or reverse the multistage carcinogenesis. Chemopreventive agents can act in any stages of carcinogenesis, i.e. initiation, promotion or progression. The intervention of cancer in the promotion stage, however, seems to be most appropriated and practical since tumor promotion is a reversible event, which requires repeated and prolonged exposure to promoting agents. Accordingly, tumor promotion is closely linked to oxidative stress and inflammation (8), and it is hence likely that compounds with strong antioxidative and anti-inflammatory activity act as anti-tumor promoters as well. In the present study we evaluate the anti-promotion potential of AT by assessing the effect of AT on TPA-induced oxidative stress and inflammation in mouse skin for short-term study.

The well-known concept of initiation-promotion leading to formation of papillomas and then conversion to carcinomas has been described (9). For example, the initiation stage is an irreversible step where genetic changes have been shown to occur in gene(s) controlling differentiation, whereas the stage of promotion is a reversible step controlling the expansion of the initiated cells. The multistage mouse skin carcinogenesis model is an ideal system to study many biochemical alterations, 
changes in cellular functions and histological changes that take place during the different stages of chemical carcinogenesis $(10,11)$. Studies have shown that skin applications of most tumor-promoting agents such as 12-O-tetradecanoyl-phorbol13 -acetate (TPA) result in inflammatory responses, including development of edema, hyperplasia, and induction of COX-2 protein expression (12-14). In addition, TPA and other tumor promoters have been shown to exert their action by production of ROS $(15,16)$. ROS may induce chromosomal aberrations, structural genetic changes resulting in alterations in gene expression with high efficiency. Moreover, Benzo[a]pyrene $(\mathrm{B}[\mathrm{a}] \mathrm{P})$, an environmental carcinogen from crude tar, is responsible for the development of skin cancer. Herein, B[a]P and TPA were used to initiate and promote, respectively, the formation of skin tumors in female CD-1 mice (9) and the effect of AT on TPA's promoting action was evaluated. The results demonstrate that AT possesses anti-promotion properties and may play a role in chemoprevention.

\section{Materials and methods}

Chemicals and reagents. Benzo[a]pyrene (B[a]P), TPA and other chemicals were purchased from Sigma Chemical Co. (St. Louis, Mo, USA). AT was synthesized by Dr Y.-J. Lee (1). Anti-COX-2, anti- $\alpha$-tubulin antisera (Transduction Laboratories, Lexington, KY) and a protein assay kit (BioRad Lab. Ltd., Watford, Herts, UK) were obtained as indicated.

Animals. Female ICR mice aged six weeks (National Laboratory Animal Center, National Science Council, Taiwan) were approved by the Animal Center Committee of CSMU and kept in an animal facility for one week before being used. The mice were provided with food and water ad libitum and kept under a 12-h light/dark cycle. The dorsal region of each mouse was shaved with electric clippers two days before treatment with AT, TPA or B[a]P. AT was given 5 min before TPA administration.

Determination of free radical quenching capacity. The free radical quenching capacity of AT was tested according to a method of bleaching stable 1,1-diphenyl-2-picrylhydrazyl (DPPH) (17). A reaction mixture containing methanol (3 ml), DPPH $(10 \mathrm{mM}, 30 \mu \mathrm{l})$, and various concentrations of tested sample was allowed to stand at room temperature for $30 \mathrm{~min}$ before mixing with redistilled water $(1 \mathrm{ml})$ and toluene $(3 \mathrm{ml})$. The solution was then centrifuged, and the absorbance of the upper phase was read at $517 \mathrm{~nm}$ against a blank.

Determination of $\mathrm{H}_{2} \mathrm{O}_{2}$ in mouse epidermis. The dorsal shaven area of mouse skin was treated topically with acetone $(200 \mu 1)$, TPA $(5 \mathrm{nmol})$ in acetone or AT $(0.5,1.2 .5 \mathrm{mM}$ in acetone) along with TPA twice with an interval of $20 \mathrm{~h}$. Animals were sacrificed $1 \mathrm{~h}$ after the second drug application by cervical dislocation. To determine the amount of $\mathrm{H}_{2} \mathrm{O}_{2}$ in mouse epidermis, a simple procedure was developed by modifying the method of Pick and Keisari (18). Briefly, mouse epidermis was minced with scissors in $3 \mathrm{ml}$ buffer [50 mM KH${ }_{2} \mathrm{PO}_{4}$ containing $10 \mathrm{mM}$ sodium azide ( $\mathrm{pH}$ 7.0)], homogenized with a polytron homogenizer three times for $30 \mathrm{sec}$ on ice and centrifuged at $10,000 \mathrm{rpm}$ for $20 \mathrm{~min}$. The supernatant was filtered by passing through two layers of gauze. To each $2 \mathrm{ml}$ cuvette were added $0.5 \mathrm{ml}$ supernatant and $0.5 \mathrm{ml}$ of the phenol $\mathrm{red} /$ horseradish peroxidase. The samples were incubated for $10 \mathrm{~min}$, the reaction was stopped by the addition of $100 \mu 1$ of $1 \mathrm{~N} \mathrm{NaOH}$, which was adjusted to $\mathrm{pH} 12.5$ and the absorbance was determined at $610 \mathrm{~nm}$. The final results were expressed as the equivalent of $\mathrm{H}_{2} \mathrm{O}_{2}\left(\mathrm{nmol} / \mathrm{cm}^{2}\right.$ mouse skin) based on the standard curve of $\mathrm{H}_{2} \mathrm{O}_{2}$-oxidized phenol red.

Determination of myeloperoxidase (MPO) in mouse skin. The determination of MPO was conducted according to the method of Huachen and Krystyna (19). The mouse skin was punched with a cork borer $(20 \mathrm{~mm})$, minced with scissors in $3 \mathrm{ml}$ of $0.5 \%$ hexadecyltrimenthyl ammonium bromide in potassium phosphate buffer [50 $\mathrm{mM}(\mathrm{pH} 6.0)]$ and homogenized with a polytron homogenizer three times for $30 \mathrm{sec}$ on ice. Samples were centrifuged at $10,000 \mathrm{x} g$ for $20 \mathrm{~min}$ and the supernatant was filtered by passing through two layers of gauze. To each $4 \mathrm{ml}$ acrylic cuvette were added $1.3 \mathrm{ml}$ of $25 \mathrm{mM} 4$-aminoantipyrine, $2 \%$ phenol solution and $1.5 \mathrm{ml}$ of $1.7 \mathrm{mM} \mathrm{H} \mathrm{H}_{2} \mathrm{O}_{2}$ with equilibration for 3-4 min. After the basal rate was established, a $0.3-\mathrm{ml}$ sample suspension was added and quickly mixed in the cuvette. Increases in absorbance at $510 \mathrm{~nm}$ were recorded for $4 \mathrm{~min}$. MPO activity was calculated from the linear portion of the curve and expressed as units/ $\mathrm{cm}^{2}$ mouse skin. One unit of MPO was defined as the activity that degrades $1 \mu \mathrm{mol} \mathrm{H} \mathrm{H}_{2} / \mathrm{min}$ at $25^{\circ} \mathrm{C}$.

Measurement of mouse ear edema. An assay of the TPAinduced mouse ear edema was performed by the method of Huang et al (20). TPA $(0.5 \mathrm{nmol})$ in acetone $(20 \mu \mathrm{l})$ alone, or together with $\operatorname{AT}(0.5,1,2.5 \mathrm{mM}$ in acetone) in acetone $(20 \mu \mathrm{l})$ was applied to the right ear of mice (eight mice per group). Mice in the control group received only acetone $(20 \mu \mathrm{l})$. Six hours later the mice were sacrificed by cervical dislocation and 6-mm (diameter) ear punch biopsies were collected and weighed. The increase in the mass of the ear punch of each mouse was directly proportional to the degree of inflammation.

Morphological examination of TPA-treated mouse skin. An assay of the TPA-induced epidermal morphological examination was performed by the method of Huang et al (20). The dorsal skin of female ICR mice (eight mice per group) was treated with acetone $(200 \mu 1)$, with TPA $(5 \mathrm{nmol})$ alone or with TPA $(5 \mathrm{nmol})$ plus AT pretreatment $(0.5,1,2.5 \mathrm{mM}$ in acetone) twice a day for 7 days. The mice were sacrificed by cervical dislocation $18 \mathrm{~h}$ after the last application. The dorsal skin was excised and fixed in $10 \%$ neutral buffer formalin. The skin samples were processed for histology with hematoxylin and eosin (H\&E) staining. Then leukocyte infiltration and epidermal thickness were used as indicators of morphology changes. Morphometric analysis was performed with an automatic photomicroscope (100-fold magnification) and an air ocular micrometer.

Immunoblotting analysis. To perform Western blotting, protein was resolved on SDS-PAGE gels along with the prestained protein molecular weight standards (Bio-Rad). Proteins were then blotted onto an NC membrane (Sartorius) and reacted with primary antibodies (anti-COX-2 and anti- $\alpha$-tubulin as internal 
<smiles>COc1cc(-c2cc3cc(/C=C/CO)cc(OC)c3o2)ccc1O</smiles>

Figure 1. Structure of AT.

control). The secondary antibody was a peroxidase-conjugated goat antimouse antibody. The reacted bands were revealed by enhanced chemiluminescence using an ECL commercial kit.

Preparation of epidermal homogenates and ODC assay. The dorsal shaven area of mouse skin was treated topically with acetone $(200 \mu \mathrm{l})$, TPA $(5 \mathrm{nmol})$ in acetone or TPA with the pretreatment of AT. Six hours after the treatment, the mice were sacrificed by cervical dislocation and the skin of the dorsal area was removed. In order to remove the epidermis from the dermis, the skin samples were plunged into water at $58^{\circ} \mathrm{C}$ for $30 \mathrm{sec}$ and then immediately submerged in an ice bath. The epidermis was removed from the dermis by gentle scraping and placed in $1 \mathrm{ml}$ of potassium phosphate buffer (50 mM; pH 7.7) containing dithiothreitol $(2 \mathrm{mM})$ and EDTA $(0.1 \mathrm{mM})$. The epidermis was homogenated on ice for $30 \mathrm{sec}$ with a polytron homogenizer. The epidermis homogenate was centrifuged at $20,000 \mathrm{x} \mathrm{g}$ for $20 \mathrm{~min}$ at $4^{\circ} \mathrm{C}$ and the supernatant fraction was removed and stored overnight at $-80^{\circ} \mathrm{C}$ before the determination of ODC activity. The ODC activity of the soluble epidermal extracts was determined by measuring the release of ${ }^{14} \mathrm{CO}_{2}$ from DL- $\left[{ }^{14} \mathrm{C}\right]$ ornithine hydrochloride and measured by liquid scintillation counting (20). Protein was determined by protein assay, using bovine serum albumin as the standard.

Two-stage mouse-skin carcinogenesis test. In two-stage mouse-skin carcinogenesis test, the dorsal regions of female ICR mice (eight animals per group) were shaved with electric clippers two days before being topically applied with $200 \mu 1$ of acetone (solvent control) or B[a]P (200 nmol) in $200 \mu 1$ of acetone as an initiating treatment. One week after the initiation, mice were treated with TPA $(5 \mathrm{nmol})$ in $200 \mu \mathrm{l}$ of acetone alone or TPA with the pretreatment of AT $(0.5,1,2.5 \mathrm{mM}$ in acetone) to the skin three times weekly for 12 weeks. Skin tumors with a diameter larger than $1 \mathrm{~mm}$ were counted and recorded every week and the incidence of papillomas was examined weekly (21).

Statistical analysis. The results were reported as the mean \pm SE and statistical significance was determined by the MannWhitney rank sum test.

\section{Results}

Free radical quenching capacity of AT. To determine the free radical quenching capacity of AT (Fig. 1), the bleaching of DPPH by AT was measured firstly. The result demonstrated in

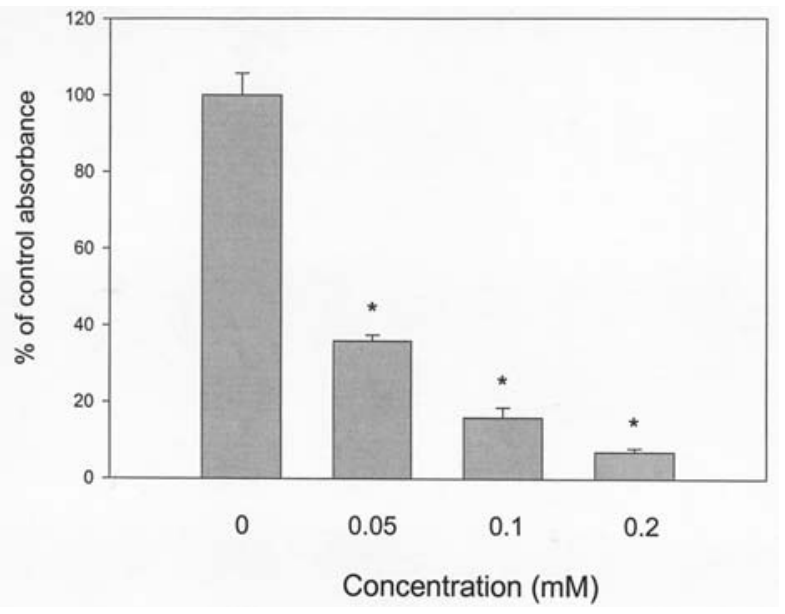

Figure 2. Effect of AT on quenching DPPH. Various concentrations of AT were added and results were analyzed by measuring the absorbance at $517 \mathrm{~nm}$. Percentage of DPPH bleaching $=$ [(absorbance of DMSO - absorbance of AT $) /$ absorbance of DMSO] x100. * $\mathrm{P}<0.0001$, compared with solvent control $(\mathrm{n}=3)$.

Table I. Inhibitory effect of AT on the formation of $\mathrm{H}_{2} \mathrm{O}_{2}$ in mouse epidermis treated with TPA.

\begin{tabular}{llrl}
\hline Group & Treatment $^{\mathrm{a}}$ & $\mathrm{H}_{2} \mathrm{O}_{2} / \mathrm{nmol} / \mathrm{cm}^{2}$ & Inhibition (\%) \\
\hline 1 & Acetone & $5.78 \pm 1.49$ & - \\
2 & TPA & $16.56 \pm 4.66$ & - \\
3 & AT $(2.5 \mathrm{mM})$ & $5.31 \pm 1.63$ & - \\
4 & AT $(0.5 \mathrm{mM})+$ TPA & $7.57 \pm 3.26^{\mathrm{c}}$ & 83 \\
5 & AT $(1.0 \mathrm{mM})+$ TPA & $6.84 \pm 2.72^{\mathrm{c}}$ & 90 \\
6 & AT $(2.5 \mathrm{mM})+$ TPA & $6.14 \pm 3.28^{\mathrm{c}}$ & 96 \\
\hline
\end{tabular}

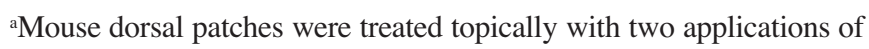
acetone $(200 \mu 1)$, TPA $(5 \mathrm{nmol})$ in acetone $(200 \mu 1)$ or TPA $(5 \mathrm{nmol})$ with pretreatment of AT in acetone $(200 \mu 1)$. The two applications were $20 \mathrm{~h}$ apart. Animals were sacrificed by cervical dislocation $1 \mathrm{~h}$ after the second TPA application and skins were removed for $\mathrm{H}_{2} \mathrm{O}_{2}$ assay. ${ }^{\mathrm{b}} \%$ of inhibition $=[$ Group $2-$ Group $4($ or 5 or 6$) /$ Group 2 Group 1] $\times 100 .{ }^{\mathrm{P}} \mathrm{P}<0.01$, compared with the group treated with TPA alone.

Fig. 2 showed that AT was able to quench the DPPH free radicals in a dose-dependent manner. AT in the concentration of $0.05 \mathrm{mM}$ quenched $\sim 64 \%$ of free radicals and DPPH almost diminished at the dose of $0.2 \mathrm{mM} \mathrm{AT}$.

Inhibitory effect of AT on TPA-induced $\mathrm{H}_{2} \mathrm{O}_{2}$ production and $M P O$ activation. To further investigate the antioxidative activity of AT in vivo we used the ICR mouse as a model to examine the effect of AT on TPA-induced $\mathrm{H}_{2} \mathrm{O}_{2}$ production. Two applications of TPA ( $5 \mathrm{nmol}), 20 \mathrm{~h}$ apart, enhanced the production of $\mathrm{H}_{2} \mathrm{O}_{2}$ by $\sim 3$-fold in comparison with the controls in mouse epidermis (Table I). The TPA ( $5 \mathrm{nmol})$-mediated production of $\mathrm{H}_{2} \mathrm{O}_{2}$ was significantly suppressed (83\%, $90 \%$ and $96 \%)$ by pretreatment with AT $(0.5,1,2.5 \mathrm{mM})$ respectively. 
Table II. Inhibitory effect of AT on the MPO activity in mouse skin treated with TPA.

\begin{tabular}{llcl}
\hline Group & Treatment & MPO/units/cm & Inhibition $(\%)^{\mathrm{b}}$ \\
\hline 1 & Acetone & $12.36 \pm 5.23$ & - \\
2 & TPA & $344.53 \pm 55.05$ & - \\
3 & AT $(2.5 \mathrm{mM})$ & $15.76 \pm 8.87$ & - \\
4 & AT $(0.5 \mathrm{mM})+$ TPA & $150.66 \pm 39.06^{\mathrm{c}}$ & 58 \\
5 & AT $(1.0 \mathrm{mM})+$ TPA & $141.76 \pm 38.43^{\mathrm{c}}$ & 61 \\
6 & AT $(2.5 \mathrm{mM})+$ TPA & $21.29 \pm 5.24^{\mathrm{c}}$ & 97 \\
\hline
\end{tabular}

${ }^{a}$ Mouse dorsal patches were treated topically with two applications of acetone $(200 \mu 1)$, TPA $(5 \mathrm{nmol})$ in acetone $(200 \mu 1)$ or TPA $(5 \mathrm{nmol})$ with pretreatment of AT in acetone $(200 \mu 1)$. The two applications were $20 \mathrm{~h}$ apart. Animals were sacrificed $1 \mathrm{~h}$ after the second TPA application and skins were removed for MPO assay. ${ }^{\mathrm{b}} \%$ of inhibition $=[$ Group $2-$ Group 4 (or 5 or 6)/Group $2-$ Group 1] x 100 . c $\mathrm{P}<0.0001$, compared with the TPA-treated group.

Table III. Inhibitory effect of AT on TPA-induced edema of mouse ear.

Group Treatment
Weight/punch/ Inhibition (\%)
mg

\begin{tabular}{llrc}
\hline 1 & Acetone & $7.6 \pm 1.5$ & - \\
2 & TPA & $12.9 \pm 1.1$ & - \\
3 & AT $(2.5 \mathrm{mM})$ & $8.0 \pm 0.8$ & - \\
4 & AT $(0.5 \mathrm{mM})+$ TPA & $10.5 \pm 1.0^{\mathrm{c}}$ & 45 \\
5 & AT $(1.0 \mathrm{mM})+$ TPA & $9.3 \pm 1.7^{\mathrm{d}}$ & 68 \\
6 & AT $(2.5 \mathrm{mM})+$ TPA & $7.8 \pm 0.8^{\mathrm{d}}$ & 96 \\
\hline
\end{tabular}

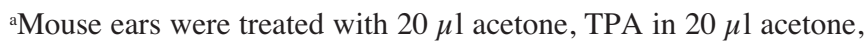
or TPA $(0.5 \mathrm{nmol})$ with the pretreatment of AT in acetone. Five hours later, the mice were sacrificed and ear punches (diameter $6 \mathrm{~mm}$ ) were weighed. ${ }^{b} \%$ of inhibition $=[$ Group 2-group 4 (or 5 or 6$) /$ Group 2-group 1] $\times 100$. ${ }^{\mathrm{C}} \mathrm{P}<0.05,{ }^{\mathrm{d}} \mathrm{P}<0.01$, compared with TPAtreated group.

MPO levels have been used as a marker to quantitate the extent to which leukocytes that have infiltrated into the dermis produce reactive oxygen intermediates in response to topical stimuli (22). Application of TPA to mouse skin induces oxidative stress, as evidenced by numerous biochemical responses, including both significant production of $\mathrm{H}_{2} \mathrm{O}_{2}$ and also enhanced levels of MPO. Therefore, the effect of topical application of AT on the TPA-induced MPO activation was examined. Two applications of TPA (5 nmol), $20 \mathrm{~h}$ apart, enhanced the activity of MPO by 28 -fold in comparison with the controls (Table II). The TPA (5 nmol)-induced activation of MPO was significantly inhibited $(58 \%, 61 \%$ and $97 \%)$ when the skin was pretreated with $0.5,1.0$ or $2.5 \mathrm{mM} \mathrm{AT}(200 \mu \mathrm{l})$, respectively.
Table IV. Inhibitory effect of AT on TPA-induced morphological changes in epidermis.

\begin{tabular}{llcc}
\hline Group & Treatment $^{\mathrm{a}}$ & $\begin{array}{c}\text { Epidermal } \\
\text { thickness }(\mu \mathrm{m})^{\mathrm{b}}\end{array}$ & $\begin{array}{c}\text { Leukocyte } \\
\text { infiltration }^{\mathrm{c}}\end{array}$ \\
\hline 1 & Acetone & $24.60 \pm 9.16$ & - \\
2 & TPA & $70.71 \pm 15.42$ & +++ \\
3 & AT $(2.5 \mathrm{mM})$ & $16.45 \pm 3.42$ & - \\
4 & AT $(0.5 \mathrm{mM})+$ TPA & $62.50 \pm 6.55$ & ++ \\
5 & AT $(1.0 \mathrm{mM})+$ TPA & $59.18 \pm 8.76^{\mathrm{d}}$ & ++ \\
6 & AT $(2.5 \mathrm{mM})+$ TPA & $57.50 \pm 2.67^{\mathrm{e}}$ & + \\
\hline
\end{tabular}

aMouse dorsal was treated topically with $200 \mu 1$ acetone, TPA $(5 \mathrm{nmol})$ in $200 \mu 1$ acetone, or TPA $(0.5 \mathrm{nmol})$ with pretreatment of AT in acetone twice a day for 7 days. Mice were sacrificed $18 \mathrm{~h}$ after last administration, and skins were processed for histological test. ${ }^{\mathrm{b}}$ The data represent the mean $\pm \mathrm{SE}$ from 5 screen fields/rat, $\mathrm{n}=8$. 'Leukocyte infiltration that was normal (-), slight (+) to severe $(+++)$ was characterized by diffuse infiltration of mononuclear infiltratory cells in dermis compared with acetone control. ${ }^{\mathrm{d}} \mathrm{P}<0.05$, eP $<0.01$, compared with the group treated with TPA alone.

Inhibitory effect of AT on TPA-induced mouse ear edema, mouse epidermal hyperplasia and leukocyte infiltration. The anti-inflammatory activity of AT was evaluated by determining its effect on TPA-induced edema of mouse ear. The inflammatory response triggered by TPA was characterized in a previous study (23). The ear punches (diameter $6 \mathrm{~mm}$ ) obtained from the right ears of mice $6 \mathrm{~h}$ after the topical application of TPA $(0.5 \mathrm{nmol})$ showed an average mass of $12.9 \mathrm{mg}$. The application of $20 \mu \mathrm{l}$ AT $(2.5 \mathrm{mM})$ prior to TPA $(0.5 \mathrm{nmol})$ inhibited the TPA-induced edema of mouse ear by $\sim 96 \%$ and AT alone did not induce ear edema (Table III). In addition, the effect of topical application of AT on TPA-mediated induction of cutaneous morphology was also assessed. As shown in Table IV, topical application of TPA $(5 \mathrm{nmol})$ twice a day for 7 days to the dorsal surface of ICR mice resulted in a 2.9-fold increase in epidermal thickness as compared to the control group. The topical application of AT before TPA application to mouse skin resulted in an inhibition in the induction of epidermal hyperplasia and inflammatory cell infiltration (Table IV). These results indicated that topical administration of AT resulted in an effective inhibition of the TPA-induced skin inflammation.

Inhibitory effect of AT on TPA-induced mouse epidermal $C O X-2$ expression and $O D C$ activation. Substantial evidence has suggested that elevation of COX-2 is not only implicated in inflammation but also in tumorigenesis (24). Thus, we next assessed the effects of skin application of AT on TPA-induced epidermal COX-2 protein expression. Western blot analysis revealed that treatment of TPA $(5 \mathrm{nmol})$ for $6 \mathrm{~h}$ increased epidermal expression of COX-2 protein, however, pretreatment with AT before TPA application decreased the expression of COX-2 protein (Fig. 3). Furthermore, since it is reported that inflammation mediates ODC activation which is essential in 


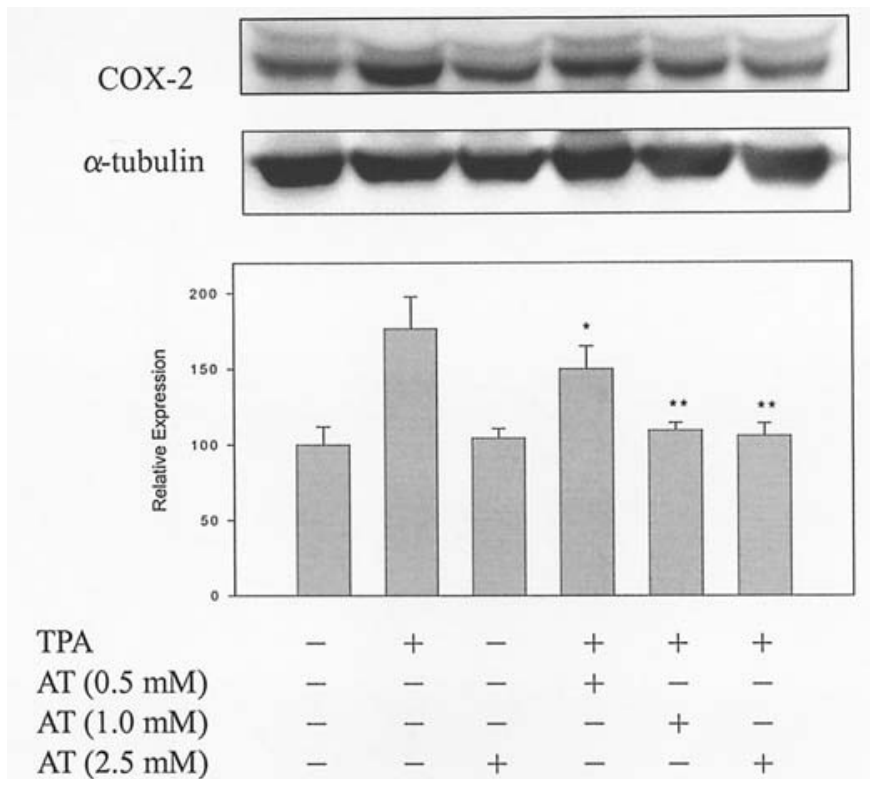

Figure 3. Effect of AT on the COX-2 expression of epidermis after TPA administration. Mouse dorsal shaven area was treated topically with acetone (200 $\mu 1)$, TPA $(5 \mathrm{nmol})$ in $200 \mu 1$ acetone or TPA with the pretreatment of AT in acetone. Six hours after the treatment, the mice were sacrificed and the epidermis was removed for Western blot analysis of COX-2 as described in the text. Three independent experiments were conducted and showed the same pattern of changes in the levels of COX-2. ${ }^{*} \mathrm{P}<0.05,{ }^{* *} \mathrm{P}<0.01$, compared with the group treated with TPA alone.

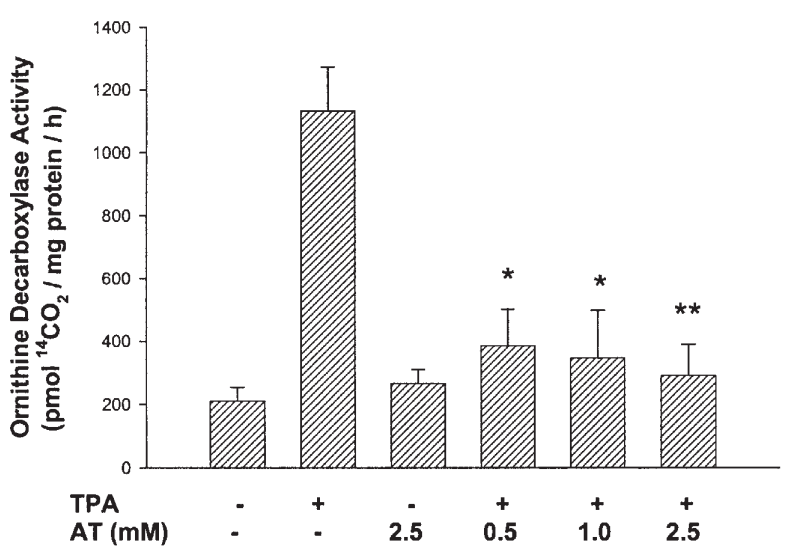

Figure 4. Inhibitory effect of topical application of AT on TPA-induced epidermal ornithine decarboxylase. Mice dorsal patches were treated topically with $200 \mu 1$ acetone, TPA $(5 \mathrm{nmol})$ in $200 \mu 1$ acetone, or TPA with the pretreatment of AT in acetone. Six hours after the treatment, the mice were sacrificed and the epidermis was removed for ODC assay. The data was presented as pmol $\mathrm{CO}_{2} / \mathrm{mg}$ protein $/ \mathrm{h} .{ }^{*} \mathrm{P}<0.001,{ }^{* *} \mathrm{P}<0.0001$, compared with the group treated with TPA alone $(n=8)$.

mouse skin tumor promotion (25) we studied the effect of AT on TPA-induced epidermal ODC activity. The results show that topical administration of TPA resulted in a significant increase in epidermal ODC activity at 6-h treatment compared to the control group. The induction was significantly diminished by the pretreatment of AT (Fig. 4). The administration of AT alone at a concentration of $2.5 \mu \mathrm{M}$ did not produce any change in epidermal ODC activity as compared with vehicle-treated animals (control).
A

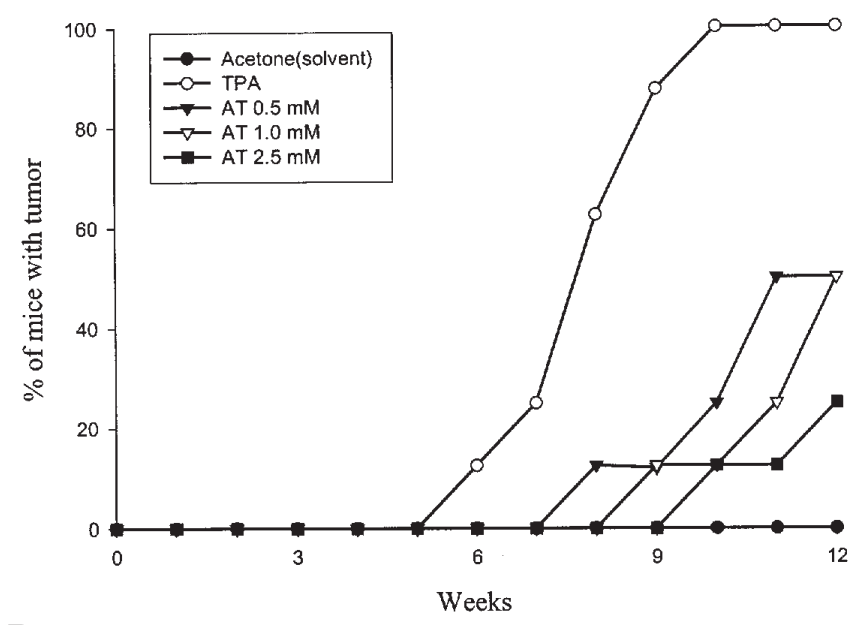

B

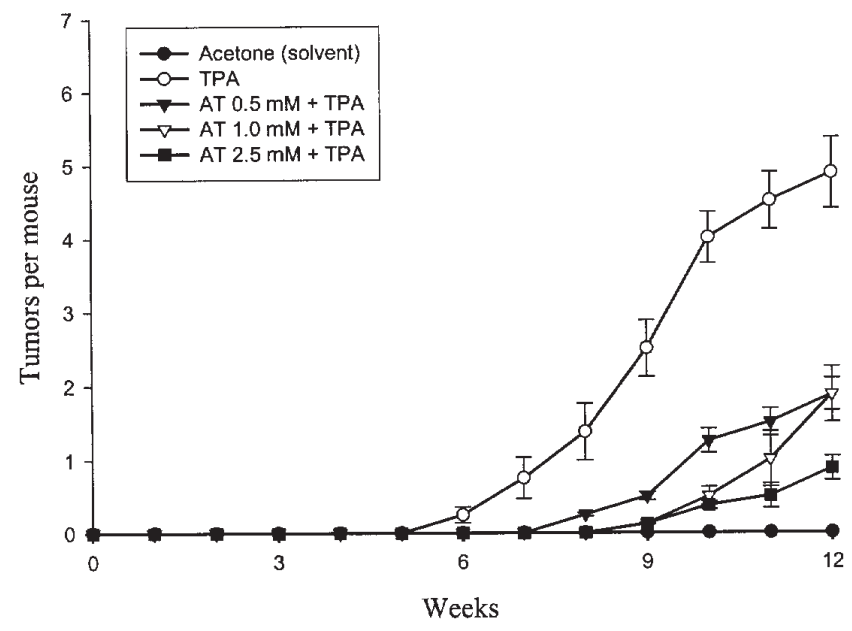

Figure 5. Inhibitory effect of topical application of AT on TPA-induced tumor promotion in mouse skin. Mouse dorsal shaven area was treated topically with $200 \mathrm{nmol} \mathrm{B}[\mathrm{a}] \mathrm{P}$ as initiator. One week after the initiation, the mice were promoted with $5 \mathrm{nmol}$ TPA as promoter three times weekly or TPA with the pretreatment of AT for 12 weeks. Skin tumors with a diameter $>1 \mathrm{~mm}$ were counted and recorded every week $(\mathrm{n}=8)$. (A) \% of mice bearing skin tumors. (B) Average number of skin tumors per mouse.

Inhibitory effect of AT on TPA-induced tumor promotion. We have shown that AT possesses antioxidant and antiinflammatory activity; therefore, it may possess anti-tumor promotion potential. In support of this possibility, the inhibitory effects of AT on TPA-induced tumor promotion were assessed. Fig. 5 shows the effect of pretreatment of AT on TPA-induced mouse skin carcinogenesis. The first tumor was observed at the 6th week in the positive control group. All the animals were observed for 12 weeks. The positive control group, which received treatment with initiator $(\mathrm{B}[\mathrm{a}] \mathrm{P})$ and $\mathrm{TPA}$, showed $100 \%$ incidence of papillomas within 10 weeks (Fig. 5A). The animals, which were pretreated with AT (0.5-2.5 mM) showed $50 \%$ and $25 \%$ papilloma formation at the end of 12 weeks. These tumor inhibitory effects were also seen as a reduction in the multiplicity of papillomas (Fig. 5B). In the TPA-treatment alone group, the average number of papillomas per mouse was 4.9 at the 12 th week, however, the group that was pretreated with AT $(0.5,1.0$ and $2.5 \mathrm{mM})$ had $1.9,1.9$ and 0.8 papillomas per mouse respectively. 


\section{Discussion}

There is accumulating evidence for the association between inflammatory tissue damage and the process of cancer development (26). Inflammation can originate from both infectious and non-infectious processes of chronic injury or irritation. The inflammatory response leads to the recruitment of mast cells and leukocytes to the site of damage with a subsequent release of free radicals, including reactive oxygen species (ROS) (27). These free radicals are known to damage macromolecules, including lipids and DNA. There is accumulating evidence for the involvement of ROS in multistage carcinogenesis. In addition, the release of eicosanoids triggers cell proliferation (26). The combinations of these processes facilitate carcinogenesis. So, the antioxidative and anti-inflammatory agents may decrease the risk of cancers. From our results AT exhibits antioxidative and anti-inflammatory properties in CD-1 mouse skin (Fig. 2; Table I-IV). Therefore, AT may play a role in chemoprevention and decrease the risk of tumor.

It is well known that cyclooxygenase (COX), an important enzyme involved in mediating the inflammatory process, catalyzes the rate-limiting step in the synthesis of prostaglandins from arachidonic acid. There are two isoforms of COX, designated COX-1 and COX-2, respectively. COX-1 is expressed constitutively in most tissues and appears to be responsible for maintaining normal physiological functions. In contrast, COX-2 is detectable in only certain types of tissue and is induced transiently by growth factors, pro-inflammatory cytokines, tumor promoters and bacterial toxins $(28,29)$. Accordingly Chun et al reported that there is a growing body of compelling evidence that targeted inhibition of COX-2 expression or activity is valuable for not only alleviating inflammation (24), but also preventing cancer. Similarly, Fig. 3 demonstrates that AT reduced the expression of COX2 induced by TPA in mouse epidermis. Furthermore, it is reported that inflammation mediated the activation of ODC (25), a rate-limiting enzyme in mammalian polyamine biosynthesis. Thus, the induction of ODC has been suggested to play a significant role in tumor promotion. Fig. 4 shows that AT inhibits TPA-mediated induction of epidermal ODC activity. Therefore, it is primarily suggested that AT might play a role in chemoprevention against tumor promotion.

Recently, much attention has been devoted to identifying cancer chemopreventive phytochemicals of dietary and medicinal origin (30). It has been reported that phenolic compounds ubiquitous in vegetables and fruits possess chemopreventive potential. On the other hand, lignans and neolignans are the other groups in nature that were found to exhibit a broad range of biological activity such as anticancer (5), antiviral (4) and anti-platelet (31). For instance, AT, a neolignan, was isolated from the chloroform-soluble fraction of stem woods of Zanthoxylum ailanthoides and the aqueous extracts of Salvia miltiorrhiza Bunge (Danshen), respectively. However, the biological properties are not well known. On the basis of the results of the in vitro assays described above, we determined subsequently the inhibitory effects of AT in a two-stage carcinogenesis test in mouse skin using B[a]P as an initiator and TPA as a promoter. The incidence (\%) of papilloma-bearing mice and the average numbers of papillomas per mouse are presented in Fig. 5A and B, respectively. From the results of two-stage carcinogenesis tests, it may be suggested that AT may be useful as an agent that inhibits chemical carcinogenesis. Similarly, those observations are consistent with our previous findings that compounds which possess antioxidant are able to inhibit the growth of tumor cells. Based upon structure analysis of AT, its structure possesses the functional groups of lignans and neolignans. In addition, our results shed light on the action of phytochemicals, such as neolignans, which might explain the protective action of Chinese herbs on the progression of cancer. Although our results support this assumption, we still need more information or detailed mechanistic study to provide an understanding of the structure-activity relationship.

In summary, AT reduced the incidence of skin tumor in a two-stage carcinogenesis model, the molecular mechanisms of which involved the antioxidant and anti-inflammatory effect of AT. Other anti-carcinogenesis potentials of AT are being studied.

\section{Acknowledgements}

This work was supported by a National Science Council grant (NSC 93-2745-B-040-010-URD) and a Chung Shan Medical University grant (CSMU 93-OM-A-083).

\section{References}

1. Lin SY, Chen CL and Lee YJ: Total synthesis of ailanthoidol and precursor XH14 by Stille Coupling. J Org Chem 68: 2968-2971, 2003

2. Sheen WS, Tsai IL, Teng CM and Chen IS: Nor-neolignan and phenyl propanoid from Zanthoxylum ailanthoides. Phytochemistry 36: 213-215, 1994.

3. Yang Z, Hon MH, Chui KY, Xu HM, Lee CM, Cui YX, Wong HNC, Poon CD and Fung BM: Naturally occurring benzofuran: isolation, structure elucidation and total synthesis of 5-(3-hydroxypropyl)-7-methoxy-2-(3'-methoxy-4'hydroxyphenyl)- 3-benzo[b]furancarbaldehyde, a novel adenosine $\mathrm{A}_{1}$ receptor ligand isolated from salvia miltiorrhiza bunge (danshen). Tetrahedron Lett 32: 2061-2064, 1991.

4. Craigo J, Callahan M, Huang RCC and DeLucia AL: Inhibition of human papillomavirus type 16 gene expression by nordihydroguaiaretic acid plant lignan derivatives. Antiviral Res 47: 19-28, 2000

5. Lambert JD, Meyers RO, Timmermann BN and Dorr RT: tetraO-methyl-nordihydroguaiaretic acid inhibits melanoma in vivo. Cancer Lett 171: 47-56, 2001.

6. Day SH, Chiu NY, Tsao LT, Wang JP and Lin CN: New lignan glycosides with potent antiinflammatory effect, isolated from Justicia ciliata. J Nat Prod 63: 1560-1562, 2000.

7. Carini M, Aldini G, Orioli M and Facino RM: Antioxidant and photoprotective activity of a lipophilic extract containing neolignans from Krameria triandra roots. Planta Med 68: 193-197, 2002.

8. De Flora S and Ferguson LR: Overview of mechanisms of cancer chemopreventive agents. Mutat Res 591: 8-15, 2005.

9. Furstenberger G, Berry DL, Sorg B and Marks F: Skin tumor promotion by phorbol esters is a two-stage process. Proc Natl Acad Sci USA 78: 7722-7726, 1981.

10. Katiyar SK and Mukhtar H: Inhibition of phorbol ester tumor promoter 12-O-tetradecanoylphorbol-13-acetate-caused inflammatory responses in SENCAR mouse skin by black tea polyphenols. Carcinogenesis 18: 1911-1916, 1997.

11. Slaga TJ, Fischer SM, Weeks CE, Klein-Szanto AJP and Reiners J: Studies on the mechanisms involved in multistage carcinogenesis in mouse skin. J Cell Biochem 18: 99-119, 1982.

12. Chun KS, Kang JY, Kim OH, Kang H and Surh YJ: Effects of yakuchinone A and yakuchinone B on the phorbol ester-induced expression of COX-2 and iNOS and activation of NF-kappaB in mouse skin. J Environ Pathol Toxicol Oncol 21: 131-139, 2002 
13. La E, Muga SJ, Locniskar MF and Fischer SM: Altered expression of interleukin-1 receptor antagonist in different stages of mouse skin carcinogenesis. Mol Carcinog 24: 276-286, 1999.

14. Seo HJ, Park KK, Han SS, Chung WY, Son MW, Kim WB and Surh YJ: Inhibitory effects of the standardized extract (DA-9601) of Artemisia asiatica Nakai on phorbol esterinduced ornithine decarboxylase activity, papilloma formation, cyclooxygenase- 2 expression, inducible nitric oxide synthase expression and nuclear transcription factor kappa $\mathrm{B}$ activation in mouse skin. Int J Cancer 100: 456-462, 2002.

15. Nakamura Y, Kozuka M, Naniwa K, Takabayashi S, Torikai K, Hayashi R, Sato T, Ohigashi H and Osawa T: Arachidonic acid cascade inhibitors modulate phorbol ester-induced oxidative stress in female ICR mouse skin: differential roles of 5-lipoxygenase and cyclooxygenase-2 in leukocyte infiltration and activation. Free Radic Biol Med 35: 997-1007, 2003.

16. Athar M: Oxidative stress and experimental carcinogenesis. Indian J Exp Biol 40: 656-667, 2002.

17. Ursini F, Maiorino M, Morazzoni P, Roveri A and Pifferi G: A novel antioxidant flavonoid (1dB 1031) affecting molecular mechanisms of cellular activation. Free Radic Biol Med 16: 547-553, 1994.

18. Pick E and Keisari Y: A simple colorimetric method for the measurement of hydrogen peroxide produced by cells in culture. J Immunol Methods 38: 161-170, 1980.

19. Huachen W and Krystyna F: Suppression of tumor promoter induced oxidative events and DNA damage in vivo by sarcophytol A: a possible mechanism of antipromotion. Cancer Res 52: 2298-2303, 1992.

20. Huang MT, Ho CT, Wang ZY, Ferraro T and Finnegen-Olive T: Inhibitory effect of topical application of a green tea polyphenol fraction on tumor initiation and promotion in mouse skin. Carcinogenesis 13: 947-954, 1992.
21. Tseng TH, Hsu JD, Lo MH, Chu CY, Chou FP, Huang CL and Wang CJ: Inhibitory effect of Hibiscus protocatechuic acid on tumor promotion in mouse skin. Cancer Lett 126: 199-207, 1998.

22. Trush MA, Egner PA and Kensler TW: Myeloperoxidase as a biomarker of skin irritation and inflammation. Food Chem Toxicol 32: 143-147, 1994.

23. Young JM, Wagner BM and Spires DA: Tachyphylaxis in 12-0tetradecanoylphorbol acetate- and arachidonic acid-induced ear edema. J Invest Dermatol 80: 48-52, 1983.

24. Chun KS, Keum YS, Han SS, Song YS, Kim SH and Surh YJ: Curcumin inhibits phorbol ester-induced expression of cyclooxygenase- 2 in mouse skin through suppression of extracellular signal-regulated kinase activity and NF- $\mathrm{kB}$ activation. Carcinogenesis 24: 1515-1524, 2003.

25. Coussens LM and Werb Z: Inflammation and cancer. Nature 420: 860-867, 2002

26. Hussain SP, Hofseth LJ and Harris CC: Radical cause of cancer. Nat Rev Cancer 3: 276-285, 2003.

27. Prescott SM and Fitzpatrick FA: Cyclooxygenase-2 and carcinogenesis. Biochim Biophys Acta 1470: M69-M78, 2000.

28. Gately S: The contributions of cyclooxygenase-2 to tumor angiogenesis. Cancer Metastasis Rev 19: 19-27, 2000.

29. Marton LJ and Pegg AE: Polyamines as targets for therapeutic intervention. Annu Rev Pharmacol Toxicol 35: 55-91, 1995.

30. Surh YJ: Molecular mechanisms of chemopreventive effects of selected dietary and medicinal phenolic substances. Mutat Res 428: 305-327, 1999

31. Chen CC, Hsin WC, Ko FN, Huang YL, Ou JC and Teng CM: Antiplatelet arylnaphthalide lignans from Justicia procumbens. J Nat Prod 59: 1149-1150, 1996. 